Research Paper:

\title{
BMI, Abdominal Obesity and Physical Activity in Adult Candidates for Lumbar Disk Degeneration Surgery
}

\author{
Shiva Mashinchi ${ }^{1}$ (D) Zahra Hojjati-Zidashti²* (D), Shahrokh Yousefzadeh-Chabok ${ }^{3,4}$
}

1. MSc. in Sport Physiology, Department of Physical Education, Rasht Branch, Islamic Azad University, Rasht, Iran

2. Associate Professor, Department of Physical Education, Rasht Branch, Islamic Azad University, Rasht, Iran

3. Professor of Neurosurgery, Guilan Road Trauma Research Center, Guilan University of Medical Sciences, Rasht, Iran

4. Guilan Neuroscience Research Center, Guilan University of Medical Sciences, Rasht, Iran

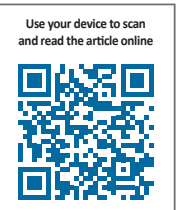

chtation: Mashinchi Sh, Hojjati-Zidashti Z, Yousefzadeh-Chabok Sh. BMI, Abdominal Obesity and Physical Activity in Adult Candidates for Lumbar Disk Degeneration Surgery. Iran J Neurosurg. 2018; 4(2):83-92. http://dx.doi.org/10.32598/irjns.4.2.83

: http://dx.doi.org/10.32598/irjns.4.2.83

\section{(c) (1) (\$)}

Funding: See Page 91

Article info:

Received: 25 October 2017

Accepted: 29 January 2018

Available Online: 01 April 2018

Keywords:

Body composition, Body mass index, Abdominal obesity, Physical activity, Lumbar disk degeneration

\begin{abstract}
Background and Aim: Lumbar DisK Degeneration (LDD) is one of the most important causes of pain in the lower back, lack of physical activity, overweight, and obesity have been regarded as the most significant factors in its occurrence. The present study was conducted with the aim of evaluation of body mass index, abdominal obesity and physical activity level in patients undergoing lumbar disk degeneration surgery.

Methods and Materials/Patients: This descriptive-analytical study was conducted on 130 adult patients (20 to 77 years old) candidates for surgery admitted to the Poursina Hospital in Rasht City, Iran in 2016 due to degenerative lumbar vertebrae diseases. After obtaining the patients' consent, their abdominal circumference, weight, and height were measured by the researcher. The Rapid Assessment of Physical Activity (RAPA) questionnaire was used to assess the level of physical activity of the subjects and questions about professional sports were asked by the researchers. SPSS 16 was used to analyze the study findings. The Chi-square test and Fisher exact test were applied to examine the relationship between qualitative data.
\end{abstract}

Results: The mean \pm SD BMI values in males and females were $26.63 \pm 4.47$ and $28.96 \pm 4.45 \mathrm{~kg} /$ $\mathrm{m}^{2}$, respectively. Also, the mean $\pm \mathrm{SD}$ values of abdominal circumference in men and women were $99.8 \pm 13.35 \mathrm{~cm}$ and $107.44 \pm 17.58 \mathrm{~cm}$, respectively. The majority of the people (88.5\%), including $71.7 \%$ of men and $97.6 \%$ of women had suboptimal physical activity, and a small percentage of samples (10.8\%) reported previous professional exercises

Conclusion: The present study results indicate the lack of activity level, high BMI and abdominal obesity in our patients. Further study is required to investigate the significant relationship between $\mathrm{BMI}$ and degenerative diseases.

\section{* Corresponding Author:}

Zahra Hojjati-Zidashti, PhD

Address: Department of Physical Education, Rasht Branch, Islamic Azad University, Rasht, Iran

Tel: +98 (911) 1482499

E-mail:z_hoj@yahoo.com 


\section{Highlights}

- About $74.6 \%$ of subjects had a body mass index higher than 25 .

- About $76.1 \%$ of men and $89.3 \%$ of women had an abdominal circumference more than normal.

- The majority of people (88.5\%) had suboptimal physical activity.

- A small percentage of individuals (10.8\%) reported previous professional exercise.

\section{Plain Language Summary}

Obesity and sedentary lifestyle account for increasing health problems nowadays. In this regard, low back pain is one of the most debilitating problems in the world. Recent research studies have focused on the role of obesity and physical inactivity in the development of lumbar degenerative disk diseases -which are among the main causes of low back pain. The current study assesses the body mass index and abdominal circumference -as the most important body composition indicators- as well as the level of physical activity in patients undergoing surgery for lumbar degenerative disc disease in Poursina Hospital in Rasht City, Iran in 2016. Based on the results of this study, 74.6\% of subjects had BMI greater than 25 and $37.7 \%$ had BMI more than 30 and the abdominal circumference of $84.6 \%$ of them was more than normal range. According to the rapid assessment of physical activity questionnaire, the majority of people $(88.5 \%)$ reported low physical activity and a small percentage $(10.8 \%)$ of them had a history of exercise. The present study confirms the previous studies based on the lack of proper physical activity and undesirable condition of body composition especially high body mass index and abdominal fat in patients with lumbar disc degenerative disease. Thus, further research is needed on the significant relationship between BMI and different kinds of degenerative disease.

\section{Introduction}

ow Back Pain (LBP) is a common and costly problem among people and one of the main causes of disability in developing countries with prevalence of $65 \%$ to $70 \%$ in general population of Iran [1, 2]. Lumbar Disk Degeneration (LDD) is known as one of the most common causes of LBP $[3,4]$ including disc hernia, spinal column stenosis, spondylosis, and spondylolisthesis.

Various factors are effective on the development of LDD, including genetic and environmental factors [5, 6]. Meanwhile, lack of physical activity [7-9] and body composition, including high Body Mass Index (BMI), obesity, overweight [10-12], and abdominal obesity $[13,14]$ have been known as the most important factors associated with LDD incidence and an increased risk of hospitalization of the affected people. In recent years, obesity, as a prevalent health problem [15], has become an independent predictor of back pain and its severity linked with disk degeneration, sciatica, and some lumbar problems $[12,16]$.

A part of a Finnish cohort study on 558 young people has shown that high $\mathrm{BMI}$ at the age of 16 was associ- ated with the incidence of DisK Degeneration (DD) at age of 21 years in men [17]. The results of a prospective study by Liuke et al. on 129 middle-aged employed men has found that BMI over 25, especially at young age, increases the risk of DD [11]. The study using MRI images on 2599 Chinese volunteers showed direct relationship between overweight/obesity and the development, progression, and worsening of LDD in young people [10]. The results of cross-sectional study on the medical records of patients admitted to Bushehr Hospital found a significant relationship between variables of increased weight, BMI, waist circumference, hip circumference and spondylolisthesis, spinal cord stenosis [12] In a part of a cohort study in Sweden, body weight is also known to increase the chance of hospitalization of patients with lumbar disc diseases [18].

The study of Takatalo et al. (2013) showed direct relationship between obesity parameters (abdominal circumference and body depth) and waist circumference with DD in men, but no such relationship in women [14]. The study of Livshits et al. (2011) on twins in England showed a significant relationship between LDD level and overweight with LBP [18]. Hangai et al. pointed out a relationship between high BMI and DD in 270 individuals [19]. 
The exact mechanism of LDD due to obesity is unclear [12], but it seems to be a combination of various factors, including mechanical causes such as continuous static pressure, increased pressure in specific positions, mechanical and chemical damage to the nerve root, immediate response of the spinal cord to increased load, longer time to restore disc height in obese individuals $[5,12]$, chronic spasms in the lumbar region due to abdominal overweight, abnormal forces on vertebrae, arthritis in the spinal column due to contraction of the lower back muscles to support abdomen [13] and other factors.

Although this belief has long lasted that body weight has harmful effects through biomechanical changes on the spinal columns, evidence suggests that biochemical and metabolic changes induced by fats (such as adipokines) can also affect developing DD. For example, elevated levels of leptin in an independent relation to BMI is associated with the development of knee arthritis in humans, and obesity is a risk factor for hand arthritis - the region with no weight-induced pressure [16] . Additionally, obesity as a risk factor for vascular-related diseases such as high cholesterol, atherosclerosis, diabetes and metabolic syndrome, is effective indirectly in developing lumbar vertebrae diseases through reducing nutrients needed by disks as well as a factor for decreasing physical activity [20].

Recent studies have also indicated the role of genetics in DD in obese individuals through collagen-9 polymorphism with synergistic effects combined with obesity, disc swelling progress, height decrease and a common inflammatory mechanism in DD progression [12]. On the other hand, the lack of physical activity is found to be an effective factor in the development and progression of intervertebral disc degeneration [7-9]. A significant relationship was observed between physical activity and pain in the lumbar region [15], especially in overweight and obese individuals [21].

Maintaining the balance between the amount of water and disc components and regular exercises prevent disc stiffness and degeneration [22] and affect moving nutrients to the disc and around it, as well as the capillary bed at the disc-bone surface [2]. Moreover, doing exercise, prevents lumbar pain through body fitness and strengthening abdominal muscles and playing a supportive role for the lumbar muscles $[1,23]$. Losing weight by doing exercise, especially in the central body area, is effective in preventing lumbar pains and problems through lowering the load pressure on the lower back, improving the lipid profile and some of the blood biochemical factors and other known mechanisms $[12,16,20]$. Additionally, performing correct exercise prevents lumbar pain and problems through improving physical positions and postures, correcting habits of standing, sitting, and the related positions in doing daily activities $[22,23]$.

After controlling sex, age, and BMI of study individuals, the prospective study of Elfering et al. reported that the lack of exercise was a significant predictor of development and progression of DD [8]. In addition, a significant relationship was observed between physical activity and pain in the lumbar region in a study on employees of Fars Province University $(P=0.02)$. Those who had exercised (regular exercise activity, continuous physical activity 20 minutes per session three times a week) experienced lower pain [15].

The disk also needs to be restored to compensate its height reduction (resulted from body upper part weight pressure and water loss) during the night rest by absorbing water and minerals. Furthermore, discs are less resistant to rotating movements of spinal column and the intense movements can rupture the outer layers of the disks [22]. Therefore, contrary to the suggested role of regular physical activity in preventing LBP and LDD $[7,8]$, increase in exercise activities [19, 24-26], especially weight lifting [2] and the evaluation of the lumbar vertebrae status of elite athletes have shown increased prevalence and more severe degenerative vertebral diseases and low back pain.

A prospective study of Baronto et al. on 71 male athletes champions in weight lifting, wrestling, cross country running and ice hockey and 21 non-athletes showed that DD was observed in more than $90 \%$ of athletes with more prevalence in weight lifting and ice hockey champions [25]. Another study was carried out on 25 long-run runners. Taking MRI images, before and after running, showed reducing length and deformity of the intervertebral disc in all three anatomical postures (flexion, extension and neutral) after one-hour running and in total, $92 \%$ of them reported to have degenerated discs [26]. Comparing the prevalence of DD in elite athletes in the 2000 Olympics with non-athletes also showed that the Olympic athletes reported increased prevalence and more severe DD than ordinary people [24]. Shobeiri et al. study recommended modifying long walking periods (more than 3 hours per day) and doing proper sport activities for the prevention of low back pain [27]. The present study aimed to assess BMI, abdominal obesity and physical activity level in adult patients who were 
candidate for lumbar disk degeneration surgery in one of the public hospitals in Rasht City, Iran.

\section{Methods and Materials/Patients}

This descriptive-analytic study included 130 adult patients (20 to 77 years old) undergoing operation due to LDD in Elective Neurosurgery Department of Poursina Hospital, Rasht City, Iran.

After obtaining consent from the research samples, their abdominal circumference and height were measured using the strip meter, and their weight was measured using the German digital scale (Beurer PS07). Then, their BMI values were calculated $[1,7]$. Standard conditions for measuring weight in this study included minimum clothing, bare feet, and standing in the middle of the scale without any help. The weight was measured in the mornings when fasting after gastrointestinal emptying $[28,29]$.

Since some of research samples were unable to stand alone due to pain or pathologic curvature and the current height is influenced by the way of standing, the height estimation method was used through ulnar bone length measurement for all patients. In this method, researchers asked the patients to bend their arms (preferably left arms) across the chest to the opposite shoulder, with the fingers on the shoulder. Then, the distance between the elbow bone and the midpoint of the wrist bone (pisiform bone) was measured using a strip meter (Figure 1). Subsequently, the height in meters was calculated by using the length of the ulna bone $(\mathrm{cm})$ and considering the age and sex of the person [30].

In this study, the abdominal circumference was measured by placing the strip meter completely horizontally around the navel and in the most prominent part of the abdomen when the patient was standing and it was rounded to the nearest $0.5 \mathrm{~cm}$ [29]. Because some patients could not move, their abdominal circumference was obtained by the researcher in supine position.

Rapid Assessment of Physical Activity (RAPA) questionnaire [31] was used to assess the level of physical activity of the subjects (on average, during one year before the sedentary life due to the complications of disease), and the samples were asked by a questionnaire about doing professional sport. The reliability and validity of RAPA had been previously examined by Khajavi and Khanmohammadi in 2015 [32]. The RAPA questionnaire consists of two parts: (a) the aerobic activities; and (b) the strength and flexibility. According to the scores of

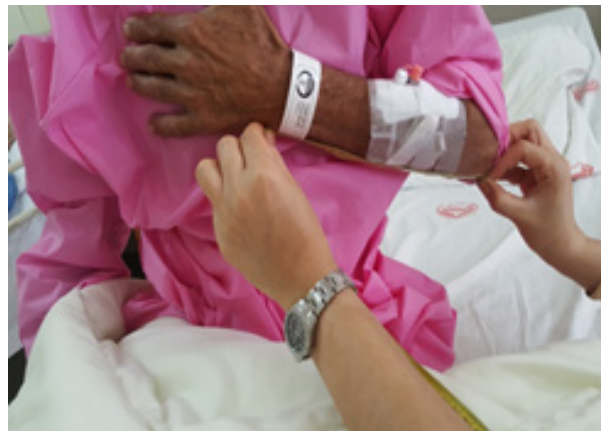

\section{INS}

Figure 1. Ulna bone length measurement to calculate height in a patient

the questionnaire, the physical activities of individuals in part (a) are divided into four groups: sedentary, underactive, under-active regular (moderate), and active. The physical activities of individuals in part (b) are divided into three groups according to strength and flexibility. After summing up the scores of the entire questionnaire items, total scores less than 6 are defined as suboptimal and individuals are categorized into two groups: 1 . Suboptimal activity group; and 2. Optimal activity group.

The samples were classified into three groups based on the type of diagnosis, the disease registered in the medical record at the time of admission: (a) disc herniation, (b) spinal column stenosis, and (c) spondylolisthesis [4].

SPSS V. 16 was used to analyze the findings of this study and the Chi-square test and Fisher exact test were applied to examine the relationship between qualitative variables. The Kolmogorov-Smirnov test was used to examine the normal distribution of quantitative data in each group. $\mathrm{P}<0.05$ was considered as the significant difference.

\section{Results}

The total number of research samples partcipating in the study was 130, whose age and sex information is presented in Table 1. In sum, they were 20 to 77 years old, with the mean $\pm S D$ age of 48.17 years (Women's mean $\pm S D$ age: $48.94 \pm 12.07 \mathrm{y}$; Men's mean $\pm S D$ age: $46.82 \pm 12.57$ y). In our study, $80(61.5 \%)$ samples had herniated disk, 41(31.5\%) suffered from listhesis, $9(6.9 \%)$ had the spinal column stenosis, and $95(73 \%)$ had their symptoms for more than one year.

The frequency, minimum, maximum, and mean values of some body composition indices of the subjects are presented in Table 2. In this study, 20 (15.4\%) patients had normal abdominal circumference, and 110 (84.6\%) had abdominal obesity. A higher percentage of women 
Table 1. Sex and age distribution of study subjects

\begin{tabular}{|c|c|c|c|}
\hline \multicolumn{2}{|c|}{ Variable } & \multirow{2}{*}{$\begin{array}{c}\text { No. } \\
84\end{array}$} & \multirow{2}{*}{$\begin{array}{c}\% \\
64.6\end{array}$} \\
\hline & Male & & \\
\hline Sex & Female & 46 & 35.4 \\
\hline \multirow{3}{*}{ Age group (y) } & $20-40$ & 38 & 29.2 \\
\hline & $41-60$ & 68 & 52.3 \\
\hline & More than 60 & 24 & 18.5 \\
\hline
\end{tabular}

compared to men had abnormal abdominal circumference (89.3\% vs. $76.1 \%$ ) (Table 3). The mean difference in male and female abdominal circumference was statistically significant $(\mathrm{P}=0.011$ ) (Table 2 ).

In addition, 97(74.6\%) subjects, including 31(67.4\%) men and 66(78.6\%) women had a BMI higher than 25 (Table 3). A total of 48(36.9\%) subjects had BMI between 25 and 30, and $49(37.7 \%)$ subjects had a BMI more than 30 .

Sudden changes in weight (about $5 \mathrm{~kg} / \mathrm{mon}$ ) were reported in $26.2 \%$ of the subjects, of which $56 \%$ suffered from abrupt weight loss. Based on Chi-square test results, a statistically significant relationship was found between the BMI values in all groups of samples with various types of lumbar vertebrae problems ( $\mathrm{P}=0.035)$ (Figure 2$)$, but this relationship between abdominal circumference and lumbar vertebrae problems was not significant in all groups $(P=0.265)$.

According to the RAPA questionnaire, 82 (97.6\%) women and $33(71.7 \%)$ men had suboptimal physical activity. Totally, 115(88.5\%) individuals showed such an activity (Table 4). Also, a small percentage of people $(10.8 \%)$ had a professional sport history, which included power and strength exercises such as wrestling and weight lifting, accounting for about $43 \%$ of professional sports in these individuals $(10.8 \%$ of total population) (Table 5).

The Fisher exact test results indicate no statistically significant relationship between the physical activity level

Table 2. Some indices of body composition in LDD patients

\begin{tabular}{|c|c|c|c|c|}
\hline Variable & & Mean士SD & Min & Max \\
\hline \multirow{3}{*}{ Weight, kg } & Women & $74.58 \pm 10.7$ & 45 & 99 \\
\hline & Men & $80.43 \pm 15.41$ & 43 & 120 \\
\hline & Total & $76.65 \pm 12.85$ & 43 & 120 \\
\hline \multirow{3}{*}{ Height, cm } & Women & $160.7 \pm 5.64$ & 145 & 182 \\
\hline & Men & $173.6 \pm 7.41$ & 152 & 188 \\
\hline & Total & $165.29 \pm 8.84$ & 145 & 188 \\
\hline \multirow{3}{*}{$\mathrm{BMI}, \mathrm{kg} / \mathrm{m}^{2}$} & Women & $28.96 \pm 4.54$ & 17.36 & 42.81 \\
\hline & Men & $26.63 \pm 4.74$ & 14.88 & 37.04 \\
\hline & Total & $28.14 \pm 4.58$ & 14.88 & 42.81 \\
\hline \multirow{3}{*}{$\begin{array}{l}\text { Abdominal circumference, } \\
\qquad \mathrm{cm}\end{array}$} & Women & $107.44 \pm 17.58$ & 70 & 174 \\
\hline & Men & $99.8 \pm 13.35$ & 62 & 124 \\
\hline & Total & $104.73 \pm 16.57$ & 62 & 174 \\
\hline
\end{tabular}


Table 3. Frequency of normal and abnormal abdominal circumference and normal and abnormal BMI in men and women

\begin{tabular}{|c|c|c|c|c|c|}
\hline \multirow{2}{*}{ Variable } & \multirow{2}{*}{ Sex } & \multicolumn{2}{|c|}{ Normal } & \multicolumn{2}{|c|}{ Higher Than Normal } \\
\hline & & No. & $\%$ & No. & $\%$ \\
\hline & Men & 11 & 23.9 & 35 & 76.1 \\
\hline \multirow[t]{3}{*}{$\begin{array}{l}\text { Abdominal } \\
\text { circumference }\end{array}$} & Women & 9 & 10.7 & 75 & 89.3 \\
\hline & Total & 20 & 15.4 & 110 & 84.6 \\
\hline & Men & 15 & 32.6 & 31 & 67.4 \\
\hline \multirow[t]{2}{*}{ BMI } & Women & 18 & 21.4 & 66 & 78.6 \\
\hline & Total & 33 & 25.4 & 97 & 74.6 \\
\hline
\end{tabular}

(RAPA index) among three groups of samples with various types of lumbar disc problems ( $\mathrm{P}=0.987$ ) (Figure 3).

The Chi-square test also revealed no statistically significant relationship between doing exercise in a professional way among three research groups with various types of lumbar vertebrae problems $(\mathrm{P}=0.968)$.

\section{Discussion}

\section{Body composition}

Our results revealed overweight and obesity in the study subjects. Inferential findings showed a significant relationship between $\mathrm{BMI}$ and degenerative disc disease type in the subjects $(P<0.05)$. The result of our study is consistent with that of many previous studies on the presence of high BMI, obesity, overweight and abdominal obesity in the LDD patients. Some of these studies are presented here. A Finnish cohort study by Takatalo et al. supported the effect of high BMI on the incidence of DD in young men [17]. The results of a prospective study by Liuke and colleagues on middle-aged men confirmed the effect of BMI, especially in young age on increasing risk of DD [11]. A population-based study supported the relationship between onset, development, and intensity of LDD in obese and overweight Chinese young volunteers [10]. A cross-sectional study on patients' medical records in one of the Bushehr's hospitals reported the relationship of weight gain, BMI, lumbar circumference, and hip circumference with the prevalence of spondylolisthesis and spinal canal stenosis [12]. Higher odds of hospitalization of LDD patients with weight gain was reported in a cohort study in Sweden [7].

Other studies with the same conclusions comprised Takatalo et al. study entitled "Association of abdominal obesity with lumbar disc degeneration" [14], Livshits et al. study on twins in England indicative of a significant relationship between LDD level and overweight with LBP [18], and Hangai et al. study on 270 individuals

Table 4. Frequency of physical activity level status

\begin{tabular}{|c|c|c|c|}
\hline \multicolumn{2}{|c|}{ Physical Activity Status } & \multirow{2}{*}{$\begin{array}{c}\text { No. } \\
33\end{array}$} & \multirow{2}{*}{$\begin{array}{c}\% \\
71.7\end{array}$} \\
\hline & Men & & \\
\hline \multirow[t]{3}{*}{ Suboptimal Activity } & Women & 82 & 97.6 \\
\hline & Total & 115 & 88.5 \\
\hline & Men & 13 & 28.3 \\
\hline \multirow[t]{2}{*}{ Optimal Activity } & Women & 2 & 2.4 \\
\hline & Total & 15 & 11.5 \\
\hline
\end{tabular}


Table 5. Frequency of professional sports types

\begin{tabular}{ccc}
\hline Professional Sports Type & No. & $\%$ \\
\hline Martial arts & 4 & 28.6 \\
Ball games & 4 & 28.6 \\
Strength sports & 6 & 42.9 \\
Total & 14 & 100 \\
\hline
\end{tabular}

about the relationship between high BMI and DD in the elderly [19].

In Takatalo et al. study, the lack of relationship between abdominal obesity indices (abdominal circumference and body depth), waist circumference and high BMI at the age of 16 years with DD incidence at the age of 21 years in women (unlike men) should be investigated in more detail $[14,17]$. In the present study, women with abnormal abdominal circumference were more than men, and a statistically significant difference was found between the mean abdominal circumference in men and women $(P=0.011)$.

Despite the consistency of the mentioned studies regarding the presence of overweight and obesity in DD patients, the result of this study is inconsistent with the results of studies conducted by Daneshjoo et al. [15] and Jones et al. [5]. These inconsistencies could indicate other factors along with the role of BMI in lumbar disk degeneration.

In addition, the demographic study of Stefan et al. (2006) on 286 males and 299 females showed that weight and BMI had no significant effect on radiographic manifestations of LDD; however, increased weight was associated with risk of osteophytes (one of the disc degeneration symptoms) [33]. The findings of the study by Videman et al. (2010) suggest that unlike current beliefs, the more physical load caused by body mass
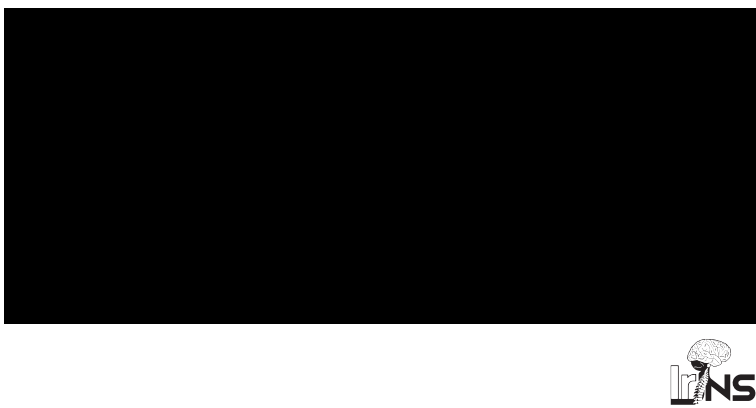

Figure 2. Frequency distribution of BMI status in three groups of patients with various types of lumbar disks problems (about 30 pounds or $13.5 \mathrm{~kg}$ on average) does not have any adverse effects on the vertebral disks. In fact, they reported a slight delay in the disk stiffness in heavier men compared to their lighter twin brothers [34].

The two recent studies results were not consistent with the present study; however, the signs of osteophyte and disc stiffness were also reported in them that along with other degenerative factors may lead finally to disk degeneration and LDD radiographic manifestations.

\section{Level of physical activity and professional sport}

Our study on the level of the physical activity of the patients with lumbar vertebrae problems revealed that most subjects had a suboptimal physical activity based on the RAPA standard questionnaire and did not have any professional experience in sports. This finding was also observed in a prospective study by Elfering et al. (2002) in which lack of exercise activities was a significant predictor of DD development and progress [8].

Daneshjoo et al. in their study on University employees in Fars Province observed a significant relationship between regular physical activity and pain relief in the waist

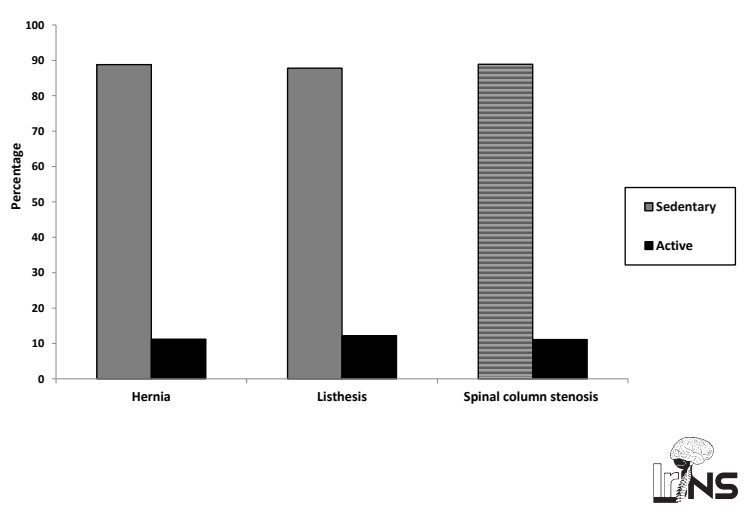

Figure 3. Frequency distribution of physical activity level (RAPA Index) in three groups of patients with various types of lumbar disks problems 
[15]. Furthermore, Videman et al. reported a moderate effect of physical activity on DD, but lower than body weight [7]. However, lifestyle factors, including irregular physical activity had no important effect on radiographic manifestations of LDD in the study by Stephen et al. [33] which indicates that irregular physical activity cannot be as effective as a regular exercise program.

Exercise is effective on the nutrients' transfer and feeding disks (increasing their concentration in the tissues around the disks and the structure of the capillary bed at the disk-bone areas) and prevents stiffness and degeneration through balancing the disk fluid [2, 22]. As the nucleus of the disc is composed of water which decreases gradually with aging, frequent exercise preserves the balance between the amount of water and disc components [22].

Moreover, sport activities prevent lumbar problems and pains through fitness, weight loss, lean body mass reduction, increased muscle mass, decreased metabolic risk factors such as obesity, strengthened abdominal muscle, and supporting role of lumbar muscles [23, 35, 36]. Lack of physical activity is known to be effective in the development of LDD and LBP [7-9].

Despite the association between the incremental exercises and professional sports [19, 24-26], especially weight lifting [2] with higher prevalence and severity of vertebral degenerative diseases and back pain in previous studies, Takatalo et al. study reported no effect on changes in back and lumbar vertebrae in MRI of professional athletes in four different sports in a 15-year prospective study which is compatible with our findings [17].

Several studies have shown opposite results which might be due to following reasons; 1 ) the studies were conducted selectively on elite and champion athletes, while the number of people who performed professional sports in the current study was very low (only 14 out of 130), and was not statistically sufficient for review, 2) the present study was performed on patients, candidate for surgery with intervertebral disc problems, while changes in intervertebral disc such as disc height in the abovementioned studies were examined with diagnostic methods such as MRI, that are more frequent compared to the advanced and debilitating stages of the disease (surgical candidates). Despite the inconsistency observed in the professional sporting, the weight lifting was mentioned in this study as one of the most frequently reported sports - albeit few - pointed out in some references [2], that the increasing load on the waist and sudden movements can be among its etiologies.
The current study had some study limitations. First, because of the conditions of the wards in public hospitals and the health status of the referring patients, the weight of the some patients could not be measured in an identical conditions in terms of the amount of eaten and excreted food or their clothing and belongings. Second, we were restricted in assessing the status of patients' physical activity and weight changing in the past due to the patients' self-reporting accompanied with difficulty in recalling and their different understandings of study concepts.

\section{Conclusion}

The present study confirms the lack of physical activity, undesirable condition of body composition, especially high BMI and abdominal fat in the studied samples. Thus, the clinicians are recommended to consider BMI, abdominal obesity, and physical activity in designing preventive and treatment protocols of lumbar vertebral problems. To generalize our findings, future studies can investigate the samples from both private as well as state hospitals or consider a control group.

\section{Ethical Considerations}

\section{Compliance with ethical guidelines}

The study was approved by research ethical committee in Guilan University of Medical Sciences with approval number: IR.IAU.RASHT.REC.1395.50.

\section{Funding}

This study was extracted from a Master's thesis and the initial steps of the clinical trial have been done.

\section{Authors contributions}

All authors have read and approved the manuscript.

\section{Conflict of interest}

The authors declared no conflict of interest.

\section{Acknowledgements}

We appreciate Dr. Mesbah Dibavand and Dr. Ahmad Kheiri, residents of Neurosurgery, Mrs. Parvaneh Roudpeyma and Saboura Rahmati, supervisors of Neurosurgery Department of Poursina Hospital and all respected nurses who did their best to support our project. We would also offer our special thanks to Poursina Clinical Research Development Unit, Guilan University of Medical Sciences, Rasht, Iran. 


\section{References}

[1] Rafeeyan Z, Mostafa Musa F. The Effectiveness of aquatic exercises on pain and disability of the patients with chronic low back pain. Evidence Based Care Journal. 2014; 3(4):39-46. [DOI: 10.22038/ EBCJ.2013.2055

[2] Urban JP, Roberts S. Degeneration of the intervertebral disc. Arthritis Research \& Therapy. 2003; 5(3):120-30. [DOI:10.1186/ar629] [PMCID]

[3] Dario AB, Ferreira ML, Refshauge KM, Lima TS, Ordoñana JR, Ferreira $\mathrm{PH}$. The relationship between obesity, low back pain, and lumbar disc degeneration when genetics and the environment are considered: A systematic review of twin studies. The Spine Journal. 2015; 15(5):1106-17. [DOI:10.1016/j.spinee.2015.02.001] [PMID]

[4] Luoma K, Riihimäki H, Luukkonen R, Raininko R, Viikari-Juntura E, Lamminen A. Low back pain in relation to lumbar disc degeneration. Spine. 2000; 25(4):487-92. [DOI:10.1097/00007632-20000215000016] [PMID]

[5] Jones G, White C, Sambrook P, Eisman J. Allelic variation in the vitamin $D$ receptor, lifestyle factors and lumbar spinal degenerative disease. Annals of The Rheumatic Diseases. 1998; 57(2):94-9. [DOI:10.1136/ard.57.2.94] [PMID] [PMCID]

[6] Battié MC, Videman T, Parent E. Lumbar disc degeneration: Epidemiology and genetic influences. Spine. 2004; 29(23):2679-90. [DOI:10.1097/01.brs.0000146457.83240.eb] [PMID]

[7] Videman T, Levälahti E, Battié MC. The effects of anthropometrics, lifting strength, and physical activities in disc degeneration. Spine. 2007; 32(13):1406-13. [DOI:10.1097/BRS.0b013e31806011fa] [PMID]

[8] Elfering A, Semmer N, Birkhofer D, Zanetti M, Hodler J, Boos N. Young investigator award 2001 winner: Risk factors for lumbar disc degeneration: A 5-year prospective MRI study in asymptomatic individuals. Spine. 2002; 27(2):125-34. [DOI:10.1097/00007632200201150-00002] [PMID]

[9] Smeets RJ, Wittink H, Hidding A, Knottnerus JA. Do patients with chronic low back pain have a lower level of aerobic fitness than healthy controls?: Are pain, disability, fear of injury, working status, or level of leisure time activity associated with the difference in aerobic fitness level? Spine. 2006; 31(1):90-7. [DOI:10.1097/01. brs.0000192641.22003.83] [PMID]

[10] Samartzis D, Karppinen J, Cheung JPY, Lotz J. Disk degeneration and low back pain: Are they fat-related conditions?. Global Spine Journal. 2013; 3(3):133-43. [DOI:10.1055/s-0033-1350054] [PMID] [PMCID]

[11] Liuke M, Solovieva S, Lamminen A, Luoma K, Leino-Arjas P, Luukkonen $\mathrm{R}$, et al. Disc degeneration of the lumbar spine in relation to overweight. International Journal of Obesity. 2005; 29(8):903-8. [DOI:10.1038/sj.ijo.0802974] [PMID]

[12] Sinaei M. [The effect of body mass index on spinal cord stenosis and spondylolisthesis in patients referring to Shohada Hospital of Persian Gulf, Bushehr, 2012-2013 (Persian)] [PhD thesis]. Bushehr: Bushehr University of Medical Sciences; 2014.

[13] Rahimi N, Raeisi H. [The prevalence of low back pain and its correlation with functional disability, quality of life, and body mass index in military staff (Persian)]. Sadra Medical Sciences Journal. 2015; 3(4):269-78.

[14] Takatalo J, Karppinen J, Taimela S, Niinimäki J, Laitinen J, Sequeiros RB, et al. Association of abdominal obesity with lumbar disc de- generation-a magnetic resonance imaging study. PLoS ONE. 2013, 8(2):e56244. [DOI:10.1371/journal.pone.0056244] [PMID] [PMCID]

[15] Daneshjoo A, Dadgar H. [The prevalence of low back pain and its relationship with physical activity, age and BMI in Fars Payam-e Noor University staff (Persian)]. Journal of Research in Rehabilitation Sciences. 2011; 7(3):302-10.

[16] Samartzis D, Karppinen J, Chan D, Luk KD, Cheung KM. The association of lumbar intervertebral disc degeneration on magnetic resonance imaging with body mass index in overweight and obese adults: A population-based study. Arthritis \& Rheumatism. 2012; 64(5):1488-96. [DOI:10.1002/art.33462] [PMID]

[17] Takatalo J, Karppinen J, Taimela S, Niinimäki J, Laitinen J, Sequeiros $\mathrm{RB}$, et al. Body mass index is associated with lumbar disc degeneration in young Finnish males: Subsample of northern finland birth cohort study 1986. BMC Musculoskeletal Disorders. 2013; 14:87. [DOI:10.1186/1471-2474-14-87] [PMID] [PMCID]

[18] Livshits G, Popham M, Malkin I, Sambrook PN, Macgregor AJ, Spector $\mathrm{T}$, et al. Lumbar disc degeneration and genetic factors are the main risk factors for low back pain in women: The UK Twin Spine Study. Annals of the Rheumatic Diseases. 2011; 70(10):1740 5. [DOI:10.1136/ard.2010.137836]

[19] Hangai M, Kaneoka K, Kuno S, Hinotsu S, Sakane M, Mamizuka $\mathrm{N}$, et al. Factors associated with lumbar intervertebral disc degeneration in the elderly. The Spine Journal. 2008; 8(5):732-40. [DOI:10.1016/j.spinee.2007.07.392] [PMID]

[20] Longo UG, Denaro L, Spiezia F, Forriol F, Maffulli N, Denaro V. Symptomatic disc herniation and serum lipid levels. European Spine Journal. 2011; 20(10):1658-62. [DOI:10.1007/s00586-011-1737-2] [PMID] [PMCID]

[21] Smuck M, Kao MC, Brar N, Martinez-Ith A, Choi J, TomkinsLane $C$. Does physical activity influence the relationship between low back pain and obesity? The Spine Journal. 2013; 13(9):S17. [DOI:10.1016/j.spinee.2013.07.071]

[22] Ehrman J, Gordon P, Visich P, Keteyian S. Clinical Exercise Physiology. Champaign: Human Kinetics; 2018.

[23] Kyley R. Prevention, treatment, and relief from back pain [Naqdi S, Ansari N, Rastgoo M Persian trans]. Tehran: Arjmand; 2010.

[24] Ong A, Anderson J, Roche J. A pilot study of the prevalence of lumbar disc degeneration in elite athletes with lower back pain at the Sydney 2000 Olympic Games. British Journal of Sports Medicine. 2003; 37(3):263-6. [DOI:10.1136/bjsm.37.3.263] [PMID] [PMCID]

[25] Baranto A, Hellström M, Cederlund CG, Nyman R, Swärd L. Back pain and $\mathrm{MRI}$ changes in the thoraco-lumbar spine of top athletes in four different sports: A 15-year follow-up study. Knee Surgery, Sports Traumatology, Arthroscopy. 2009; 17(9):1125-34. [DOI:10.1007/s00167-009-0767-3] [PMID]

[26] Dimitriadis A, Papagelopoulos P, Smith F, Mavrogenis A, Pope M, Karantanas $A$, et al. Intervertebral disc changes after $1 \mathrm{~h}$ of running: A study on athletes. Journal of International Medical Research. 2011; 39(2):569-79. [DOI:10.1177/147323001103900226] [PMID]

[27] Shobeiri E, Saeedi H, Keyhanshokooh J, Rezaei M. [MRI imaging results in patients with low back pain and radiculopathy and their relationship to demographic characters (Persian)]. Journal of Kermanshah University of Medical Sciences. 2010; 14(2):119-24.

[28] A Group of Authors. [Guide to Diet Therapy (Persian)]. Tehran: Salemi; 2001. 
[29] Abrishamkar S, Saboori M. [Fundamentals of neurology and spinal surgery (Persian)]. Isfahan: Isfahan University of Medical Sciences Publishing; 2006.

[30] Mahan LK. Krause's Food \& the Nutrition Care Process. 14th Edition. Philadelphia: Saunders; 2017.

[31] Health Promotion Research Center. How physically active are you? An assessment of level and intensity of physical activity. Washington: Health Promotion Research Center; 2009.

[32] Khajavi D, Khanmohamadi R. [Predicting depressive symptoms of the elderly according to physical activity level and demographic characteristics: Examining the role of age and gender (Persian)]. Development and Motor Learning (Harakat). 2015; 7(1):87-103.

[33] Pye SR, Reid DM, Adams JE, Silman AJ, O'neill TW. Influence of weight, body mass index and lifestyle factors on radiographic features of lumbar disc degeneration. Annals of The Rheumatic Diseases. 2007; 66(3):426-7. [DOI:10.1136/ard.2006.057166] [PMID] [PMCID]

[34] Videman T, Gibbons LE, Kaprio J, Battié MC. Challenging the cumulative injury model: Positive effects of greater body mass on disc degeneration. The Spine Journal. 2010; 10(1):26-31. [DOI:10.1016/j. spinee.2009.10.005] [PMID]

[35] Tofighi A, Ghaffari Y, Afsarbegi N. [The effects of a selected aerobic exercise along with a controlled diet on weight loss in obese men (Persian)]. Iranian Journal of Nutrition Sciences \& Food Technology. 2014; 9(2):85-94.

[36] Ghiasvand R, Hariri M, Haghighatdoost F, Darvishi L. The effect of exercise on appetite and serum ghrelin: Implications for weight control. Journal of Health System Research. 2013; 9(3):211-21. 